\title{
PERFORMANCE OF WOOD-FRAMED RESIDENTIAL STRUCTURES UNDER EXTREME WIND LOADS
}

\author{
SARAH A. STEVENSON ${ }^{1}$, GREGORY A. KOPP ${ }^{1} \&$ AYMAN M. EL ANSARY ${ }^{2}$ \\ ${ }^{1}$ Boundary Layer Wind Tunnel Laboratory, University of Western Ontario, Canada \\ ${ }^{2}$ Department of Civil and Environmental Engineering, University of Western Ontario, Canada
}

\begin{abstract}
Failures of wood-framed residential structures are among the most common and expensive types of wind damage in densely populated regions. Numerous recent studies have focused on mitigating residential damage during tornadoes and hurricanes. Past work has identified weak links in the vertical load path of wood-framed homes under uplift, focusing primarily on the roofs since their failure is common. In recent work, structural details such as connections and fasteners have been determined to have a large impact on the resilience of wood-framed homes. In this paper, common residential failure modes are reviewed, ongoing work to prevent expensive residential damage is presented, and failure wind speed estimates currently used in tornado assessment are revisited. The results of preliminary structural analyses verify the common understanding that toe-nailed roof-to-wall connections are likely to be among the most vulnerable elements in the structure of a wood-framed house. However, it is also found that certain framing members and connections display significant vulnerability under the same wind uplift, and the possibility of framing failure is not to be discounted. The analysis results and damage survey observations are used to expand the understanding of wood-framed residential roof failures, as they relate to the Enhanced Fujita scale, and address potential gaps in current residential construction practice.
\end{abstract}

Keywords: residential structures, wind hazards, tornadoes, building codes, fragility, roof failures, loss prevention, Enhanced Fujita scale.

\section{INTRODUCTION}

Extreme weather events are increasingly expensive in North America; the occurrence of hazards such as hurricanes and tornadoes is growing, and the risk of an event hitting a densely populated area increases as the population shifts towards urban areas. Research has found that annual average losses from tornadoes are as high as those from hurricanes [1], with residential damage accounting for the highest insured losses in both cases [2].

Wood-framed residential structures comprise the highest percentage of housing in North America, and they are highly susceptible to wind damage. Recent research has focused on tornado risk analysis and loss modeling for residential structures in the United States [3], [4]. This work involves understanding a complex interaction between many variables related to the hazard and the vulnerability of a community to that hazard. Romanic et al. [3] developed a tornado loss model based on five parameters; tornado occurrence, tornado intensity, exposure, vulnerability, and spatial distribution of tornado tracks. Their work included use of a vulnerability function from previous work that was deemed suitable, but the authors highlight that the assessment of structural vulnerability is one of the greatest sources of uncertainty in tornado loss modeling.

Standohar-Alfano and van de Lindt [4] used fragility information developed by others to understand the local 50 year probability of failure of the roof sheathing or roof-to-wall connection (RTWC) for houses in five US cities. Consideration of regional building practice was given by using strength data for similar connections, or adjusting the values to match the number of nails specified in local building codes. Work to understand tornado - or hurricane - risk is often limited by the availability of structural data. Although wood-framed residential 
structures are a common and critical type of infrastructure, there is a lack of scientific information on their resilience, especially when they are subjected to extreme wind loads, and there is a lack of engineering design in their construction.

Most wood-framed houses are not engineered structures, and are rather built to prescriptive standards that do not include tornado-resistant provisions. Construction methods and materials vary across regions, and they are often subject to industry "rules of thumb". Understanding the vulnerability of a specific community in a tornado-prone region requires an understanding of the local methods and accurate models or data representing the structural behavior. Ongoing research is being done to identify the weak links in residential structures under extreme winds and improve modeling methods for understanding vulnerability.

Experimental facilities exist for measuring the forces caused by straight-line and rotating winds, as well as facilities for testing the behavior of components, models, or full-scale structures subjected to those forces. However, because full-scale experimental research is expensive and time-consuming, the majority of research to identify vulnerabilities in whole structures is limited to computational studies. Analytical research is supplemented with test results for specific structural components, as well as observations from post-storm damage surveys.

\section{TORNADO DAMAGE SURVEYS}

Because measurement of wind speeds during tornadoes is practically impossible, their strength and size are assessed based on the severity of damage they cause to buildings and vegetation. Forensic damage surveys provide the opportunity for the strength and effective area of a storm to be assessed and recorded. They also allow structural researchers to understand how wind failures occur in different types of structures, facilitating development of mitigation techniques. A standardized method for assessing the intensity of a tornado using forensic observations is provided by the Enhanced Fujita (EF) scale [5]. The EF-Scale was adapted from the original Fujita scale [6], which provided wind speed estimates for different levels of damage, with residential structures being the primary Damage Indicator (DI) used for assessment. Since residential structures are the most commonly damaged type of structure, their assessment provided reliable wind speed estimates. Dense, residential neighborhoods typically display variations in damage across the width and along the length of a tornado's path. This provides detailed information about the range of wind speeds seen in an event.

The wind speed estimates given in the original Fujita [6] scale were based on the guesses of industry experts, and had never been scientifically verified. The EF-Scale [5], [7] was developed in 2006 to provide refined wind speed estimates and introduce more DI's to assist in maintaining detailed, consistent tornado reports across the continent. The EF-Scale also attempts to account for variations in construction quality by providing a range of wind speeds related to each mode of damage. The current version of the EF-Scale used in Canada [5] includes wind speed estimates for common damage observed in 31 different DI's, which include structures, vegetation, and other fixtures. Under each DI, the EF-Scale sorts the damage using categories called Degrees of Damage (DOD). DODs describe the common modes of damage in a particular DI. Each DOD is assigned lower bound, average, and upper bound wind speeds expected to cause such damage. In the present study, the DI for one - and two - family residences (FR12) is of particular interest. An example of the DOD listing for this DI is shown in Table 1.

Wind engineering researchers have been working to verify the EF-Scale wind speeds and broaden the scale to consider nuances in the construction of different DI's. For example, 
Table 1: DOD descriptions and wind speed estimates for FR12, as listed in the Canadian version of the EF-Scale. (Source: Environment Canada [5].)

\begin{tabular}{|c|l|c|c|c|}
\hline \multirow{2}{*}{ DOD } & Description of damage & \multicolumn{2}{|c|}{ Wind speed estimates $(\mathrm{km} / \mathrm{h})$} \\
\cline { 3 - 5 } & & $\begin{array}{c}\text { Lower } \\
\text { bound }\end{array}$ & Expected & $\begin{array}{c}\text { Upper } \\
\text { bound }\end{array}$ \\
\hline 1 & Threshold of visible damage & 85 & 105 & 130 \\
\hline 2 & $\begin{array}{l}\text { Loss of roof covering material (up to 20\%), gutters } \\
\text { and/or awning; loss of vinyl or metal siding }\end{array}$ & 100 & 125 & 155 \\
\hline 3 & Broken glass in door and windows & 125 & 155 & 185 \\
\hline & $\begin{array}{l}\text { Uplift of roof deck and loss of significant roof } \\
\text { covering material (more than 20\%); collapse of } \\
\text { chimney; garage doors collapse inward; failure of } \\
\text { porch or carport }\end{array}$ & 130 & 155 & 185 \\
\hline 5 & Entire house shifts off foundation & 165 & 195 & 225 \\
\hline 6 & $\begin{array}{l}\text { Large sections of roof structure removed (more } \\
\text { than 50\%); most walls remain standing }\end{array}$ & 165 & 195 & 230 \\
\hline 7 & Exterior walls collapsed & 180 & 210 & 245 \\
\hline 8 & Most walls collapsed, except small interior rooms & 205 & 245 & 285 \\
\hline 9 & All walls collapsed & 230 & 275 & 320 \\
\hline 10 & $\begin{array}{l}\text { Destruction of engineered and/or well-constructed } \\
\text { residence; slab swept clean }\end{array}$ & 265 & 320 & 355 \\
\hline
\end{tabular}

observed variations in the performance of different residential roof shapes has led to work justifying the use of separate DI's for gable- and hip-shaped roofs [8]. Research has also continued to develop alternatives for improved structural resilience by identifying the predominant weaknesses and developing tools and building code provisions to rectify them. The present research contributes to this work for residential structures by expanding the focus from two common failure modes to include an additional mode which may prevail in residential hip roofs.

Research to mitigate residential losses during tornadoes focuses primarily on the damage described under DOD4 and DOD6 in the EF-Scale, corresponding to roof sheathing failure and loss of large sections of the roof structure, respectively. Assessment of hurricane damage does not utilize the EF-Scale and the tornado wind speed estimates cannot be related directly to hurricane wind speeds; however, the wind-induced failure modes are similar in both types of storm. Roofs of wood-framed houses are known to be particularly vulnerable to high winds, with sheathing failure often resulting in loss of the entire building and contents due to rain entry, and failure of the RTWC resulting in rain entry and higher likelihood of wall collapse due to loss of lateral support. Images of the two common failure modes, as well as a new mode of DOD6 appearing to occur in the roof framing structure, are shown in Fig. 1. Framing failures such as that shown in Fig. 1(c) have not been studied previously.

\section{RESIDENTIAL ROOF FAILURES}

Research on residential roof failures has found that DOD4 and DOD6 mainly occur due to small details such as fasteners and structural connections. Gavanski et al. [9] performed a reliability analysis of sheathing panels subjected to a range of wind speeds, based on 


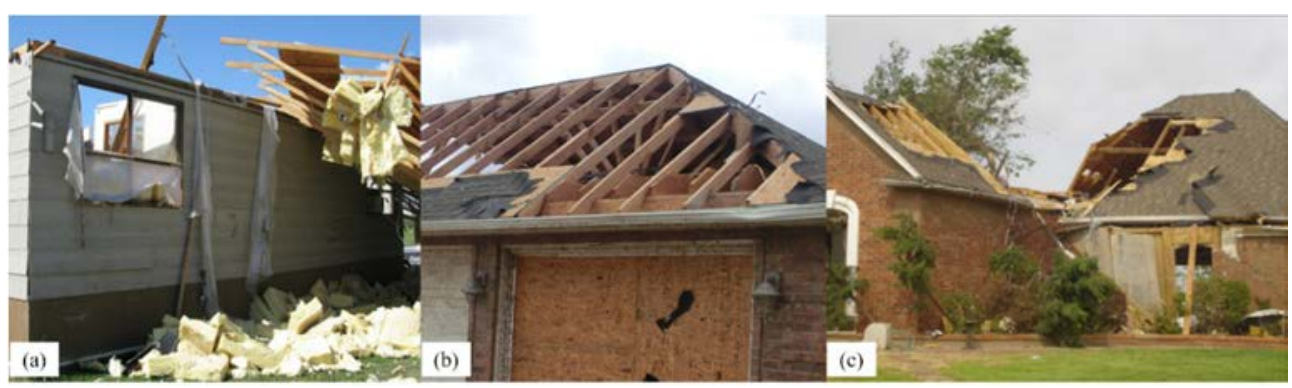

Figure 1: Residential (FR12) roof failure modes. (a) Roof-to-wall connection (RTWC) failure; (b) Sheathing loss; (c) Framing failure. (Source: Authors and Dr. D.O. Prevatt, University of Florida.)

measurements taken in cities across Canada. The analyzed sheathing layouts were designed and fastened in accordance with prescriptive standards in the National Building Code of Canada (NBCC) [10]. The analysis found that the minimum fastener requirement for most cities $-6 \mathrm{~d}(51 \mathrm{~mm})$ common wire nails at $300 \mathrm{~mm}$ spacing - is not adequate. Considering a tolerable annual failure probability of $5 \times 10^{-5}$, Gavanski et al. [9] compared the performance of $6 \mathrm{~d}$ nails to that of $8 \mathrm{~d}$ nails at the same spacing. The results show that switching from $6 \mathrm{~d}$ to $8 \mathrm{~d}$ (a $12 \mathrm{~mm}$ length increase) drastically reduces the loss of sheathing, and that reducing the fastener spacing and/or using specialized (e.g. HurriQuake) nails can prevent sheathing loss altogether in Canada's most severe wind climates.

Similar to the importance of sheathing fasteners for preventing DOD4, other studies have identified the importance of proper connection between the roof structure and the wall topplate for preventing DOD6 related to loss of large portions of the roof. Amini and van de Lindt [11] developed fragility curves depicting the probability of failure of RTWCs subjected to increasing wind speeds. Three connection types were studied: $216 \mathrm{~d}$ toenails, and $1-$ or 2 H2.5 hurricane straps. The results found that under EF2 wind speeds $(179-218 \mathrm{~km} / \mathrm{h})$, toenailed connections have a $100 \%$ probability of failure, while a single hurricane strap would reduce the probability of failure to $35-96 \%$ and two hurricane straps would reduce it further to $0-18 \%$.

In another study, Kopp et al. [12] developed fragility curves for failure of RTWCs with varying numbers of nails. This study was based on damage observations following an EF2 tornado in Angus, Ontario in June 2014. The number of toenails in the RTWCs was varied to understand the effect of construction quality on the failure wind speeds. Considering toenailed RTWCs with three nails to be "perfect" connections, in accordance with the NBCC, connections with three, two, and one toe-nail were analyzed. Inadequate RTWCs were observed in the majority of failed roofs following the Angus tornado; in some cases, there was no sign of any nails at the RTWC, while many others had only one or two nails as shown in Fig. 2. The results of the fragility analysis indicate that for gable roofs, the wind speed at the $50 \%$ failure probability is reduced from $200 \mathrm{~km} / \mathrm{h}$ to $160-170 \mathrm{~km} / \mathrm{h}$ when two nails are missing from every RTWC. The reduced wind speed at the median probability of failure is in the EF1 wind speed range. For hip roofs, the reduction was from $250 \mathrm{~km} / \mathrm{h}$ to $180-200$ $\mathrm{km} / \mathrm{h}$.

The fragility analyses in Kopp et al. [12] also provide a comparison of the sheathing and RTWC performance of gable- and hip-shaped roofs. As previously mentioned, hip roofs are 


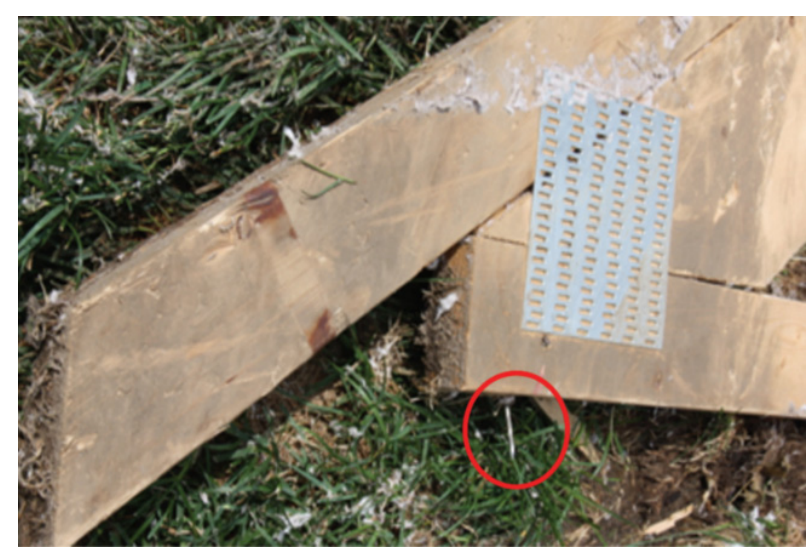

Figure 2: Failed RTWC with a single toe-nail, rather than three as required by the NBCC [10]. (Source: Kopp et al. [12].)

understood to be more resilient to wind damage than gable roofs of comparable construction quality. Pyramid-shaped hip roofs have RTWCs along all four edges, while gable roofs are connected to the wall structure only along the lower edges of two faces. The improved performance of hip roofs is considered to be the result of the number of connections, as well as preferable aerodynamic behavior [13]. Kopp et al. [12] found that when $8 \mathrm{~d}$ nails are used on the sheathing connections, gable roofs are more likely to fail at the RTWC than sheathing, and that this failure will occur within the DOD6 range. In hip roofs, failure of the RTWC and sheathing (with 8d nails) both occur at wind speeds higher than the DOD6 range. In a subsequent study, Gavanski and Kopp [8] recommend that the EF-Scale treat gable- and hiproofed homes as separate subsets of the FR12 DI, with higher failure wind speeds estimated for hip roofs. Their results found that the range of wind speeds causing DOD6 in a hip-roofed home should be estimated in the range of $258-290 \mathrm{~km} / \mathrm{h}$, versus $200-225 \mathrm{~km} / \mathrm{h}$ for gable roofs. A $10-15 \%$ reduction in the failure wind speed for roofs missing nails in the toe-nailed RTWC or a $50-60 \%$ increase for roofs using H2.5 hurricane straps were also recommended.

While the description for DOD6 encompasses all major roof failure modes, the literature indicates that the current understanding of DOD6 is limited to research focusing on the RTWC. The possibility of failure in the roof framing structure itself has been largely neglected. However, recent damage survey observations - such as those shown in Figs 1(c), 3 and 6 - have identified DOD6-level damage that, upon inspection, is found to occur in the structure rather than at the RTWC. These failures appear to occur mainly in hip roofs. The high estimated wind speeds for sheathing or RTWC failure in hip roofs, as identified in the aforementioned studies, also imply that the weak link in the vertical load path of a hip roof may occur in a different structural component. Supplementing emerging recommendations for improved sheathing and RTWC fasteners, recent and ongoing research by the authors focuses on understanding the occurrence of failures in the roof structure itself.

\section{STUDY OF FRAMING FAILURES IN HIP ROOFS}

Residential structures serve to protect people and their belonging from the elements, control the indoor environment, and provide security. In North America, house construction methods have remained relatively unchanged for many decades, with residential design evolving slowly as new technology and building code revisions are developed and implemented. 
Throughout history, it has remained constant that small residential structures are not engineered, and are rather constructed to prescriptive standards based on industry experience.

One major change to residential construction which came about in the 1950s was the invention of Metal-Plate-Connected (MPC) wood trusses. MPC trusses are pre-fabricated sections of the roof frame that are shipped to site and erected atop of the wall structure. They are being used increasingly in place of on-site, "stick-framing" methods. The trusses themselves are required to be engineered for expected snow loads, so their flexibility and connection behavior are well-understood under gravity loads. However, the overall structure including sheathing and the RTWC is not engineered, and the behavior of trusses or stickframe roofs under uplift loads have not been extensively researched. Both structure types are assessed in the current work.

The work presented in the MSc thesis of Stevenson [14] and Stevenson et al. [15] focuses on examining whether framing failures in hip roofs under uplift are possible and, if so, understanding the conditions that cause them to occur. Using tornado damage survey data obtained from colleagues at the University of Florida, the occurrence of different modes of residential roof failure in residential neighborhoods was assessed. Preliminary statistics discussed in [14], [15] show that framing failures may occur as frequently as RTWC or sheathing failures. In one study neighborhood, newer houses with steep-sloping, stick-frame roofs were of particular interest because of a high occurrence of framing failure. Similarities were observed in the houses that failed in this region. As shown in Fig. 3, the largest surface of the roof was commonly removed, while parts of the structure enclosing smaller spaces remained intact. This effect suggests either aerodynamic issues with the loading on steep roof faces, or poor member layout and connection strength in the structure of the large face. The results of the occurrence study bring attention to stick-frame structures for future, detailed modeling.

\subsection{Demand-capacity analysis of hip roof structures}

To assist in understanding the likelihood of framing failures in hip roofs, preliminary structural analyses have been performed. Trussed and stick-frame structures were analyzed using finite element modeling. The internal forces caused by wind uplift on the roof surface were estimated and compared to calculated strength values for the wood members and their connections. Detailed fragility analyses or failure modeling requires experimental strength

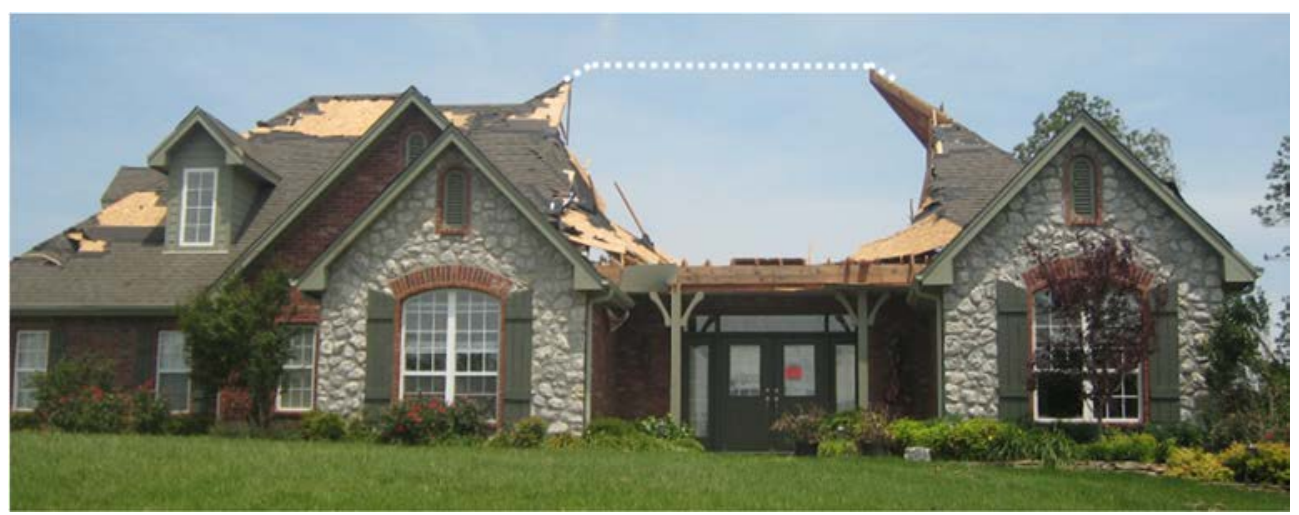

Figure 3: Failure of steep-sloping, stick-frame hip roof including removal of the largest faces. (Source: Stevenson [14] and Dr. D.O. Prevatt.) 
data - or accurate estimates - for every component of the structure. Such information is not available for MPC trusses, and it is limited for stick-frame roofs. For the present work, it is considered sufficient to model the roof structure in a simplified way, then compare the estimated forces to hand-calculated strength values. The weak links in the roof structure are identified by comparing the Demand-to-Capacity (D/C) ratios for every element in the roof. An image showing significant results for the trussed structure are shown in Fig. 4, and those for the stick-frame section are shown in Fig. 5.

The results of the D/C comparison for the MPC truss verify that the toe-nailed RTWC has the lowest relative strength by a $40 \%$ difference. The RTWC has a D/C ratio of 0.981 , while the next highest ratio is 0.695 in the top chord member at Joint 3. Variations in the element capacity, joint configuration, or load path due to area-varying pressures could shift the results in any of the $\mathrm{D} / \mathrm{C}$ ratios. However, since the analysis was based on comparison of the extreme force and capacity values, it is unlikely that the location of the weak link will shift; it is expected that toe-nailed RTWC's will almost always fail first in a trussed roof. Fig. 4 also shows the relative strength of a RTWC which uses a hurricane strap instead of toe-nails. In this case, the $\mathrm{D} / \mathrm{C}$ ratio of the hurricane strap is 0.470 , showing that application of the most

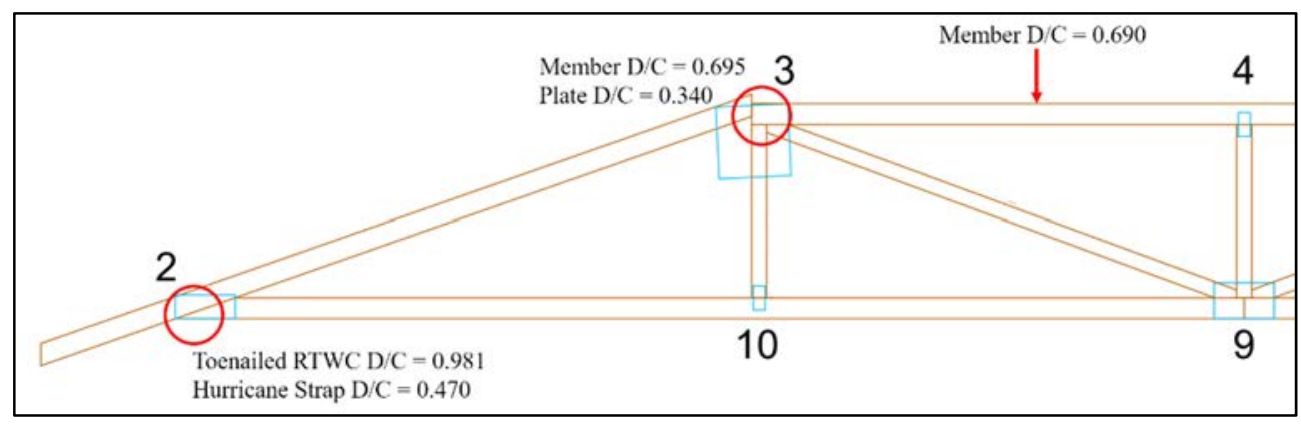

Figure 4: Diagram of modeled MPC truss showing critical demand-to-capacity ratios.

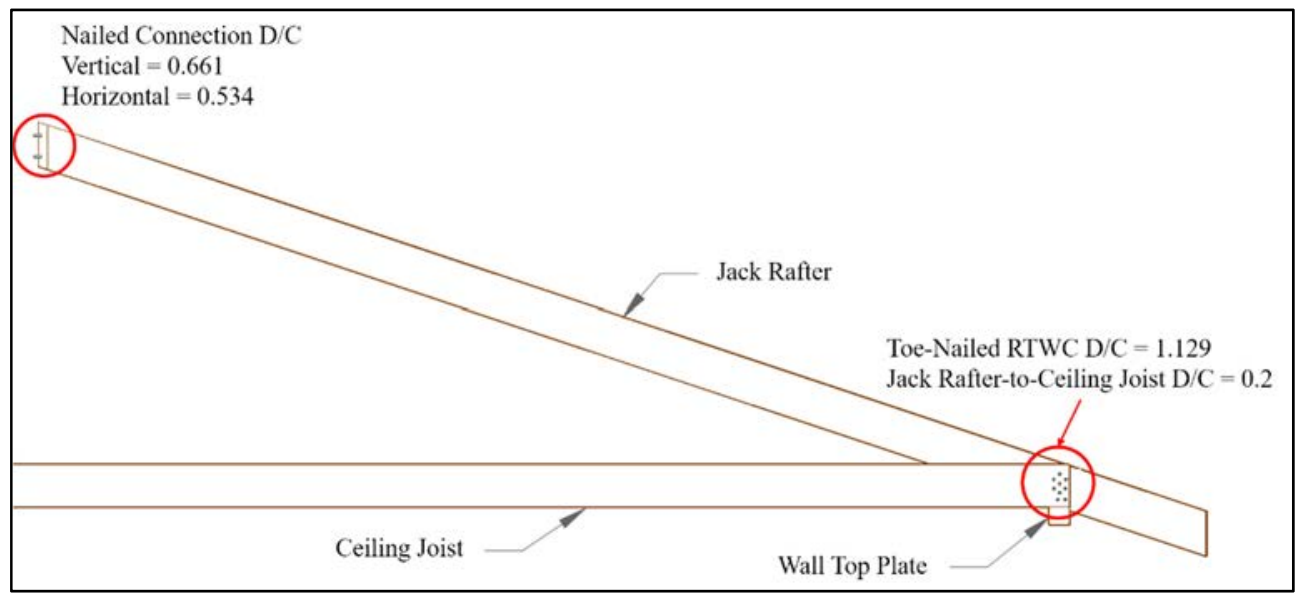

Figure 5: Diagram of modeled stick-frame section showing critical demand-to-capacity ratios. 
basic hurricane strap would shift failure into the connections within the truss. This is important because MPC joints are not currently designed for in-plane moment, which was the governing load effect at this location.

The results of a similar D/C analysis for the stick-frame section, subjected to the same uplift as the truss, are shown in Fig. 5. Similar to the truss results, analysis of the jack rafters at the center of the roof face found that it is most vulnerable at the toe-nailed RTWC. The $\mathrm{D} / \mathrm{C}$ ratio for a case including a hurricane strap was not calculated. However, introduction of a strap is expected to shift failure to the ridge joint due to the relatively high $\mathrm{D} / \mathrm{C}$ ratios in this location. As with trussed roofs, variations in material behavior may make it even more likely that framing failures will take place. This is especially probable when construction errors and flaws are considered.

Another notable result, which will be discussed in the following section, relates to the second-weakest connection at the base of the roof. In a stick-frame roof, the jack rafter is fastened to the ceiling joist using seven nails, and this connection is secured to the wall as a unit by the RTWC. Significant force would be required for the structure to fail at the rafterto-joist connection. More details of the analytical work are provided in [14], [15]. Sophisticated, three-dimensional finite element models will be required for fragility models or failure simulations to be developed in the future. Experimental studies on the failure behavior of common connections will be carried out to allow for models to be developed using accurate material properties.

\subsection{Synthesis of demand-capacity analysis and fragility results}

The results of the demand-capacity analysis in Section 4.1 are converted into equivalent wind speeds for comparison with the results of the fragility analyses in Section 3. Wind speeds at the median probability of failure for each component are collected from the literature or calculated based on the method used by Morrison et al. [16]. The strength and median wind speed for the 3-d16 toe-nail connection from [12] are used for normalization of the other data. Table 2 summarizes the results and compares the estimated failure wind speeds with the relevant range in Table 1. These results provide a number of new perspectives on the inclusion of hip roofs in the listing for FR12.

The wind speed results for toe-nailed connections in trussed hip roofs agree with those in [8]. These results suggest that the DOD6 wind speeds should be increased for hip roofs. Both studies confirm that the use of hurricane straps will shift the failure of a hip roof even further beyond the DOD6 range. In the present study, the only "major failure" wind speed that falls within the current DOD6 range is that of toe-nailed RTWCs in a stick-frame roof. DOD4 may occur first in this case, depending on the length of the sheathing fasteners. In the configurations studied, sheathing failure will occur before framing failure (neglecting RTWC failure) of either structure type; however, different fastener configurations exist that may also alter this result.

The failure wind speed for the 5-toe-nail RTWC in the stick-frame section is lower than that for the 2-toe-nail connection in a trussed roof due to the light weight of stick-frame structures and fewer internal members, which results in longer unsupported lengths and poor internal load transfer. Overall, this research agrees with the suggestion of a higher DOD6 range for hip roofs from [8]. However, regarding the poorer performance of stick-frame roofs, the present findings suggest that an additional adjustment should be proposed. Based on the recommended range of 256-288 km/h for toe-nailed hip roofs in [8], we recommend a $16 \%$ reduction for stick-frame structures. Additionally, the $50 \%$ increase for use of hurricane straps should only be $26 \%$ for stick-frame structures. 
Table 2: Comparison of wind speeds at the median probability of failure for hip roof components discussed in Section 3 and Section 4.

\begin{tabular}{|c|c|c|c|c|}
\hline Component & $\begin{array}{l}\text { Median failure } \\
\text { wind speed }\end{array}$ & $\begin{array}{l}\text { Relevant } \\
\text { DOD [5] }\end{array}$ & $\begin{array}{l}\text { Wind speed } \\
\text { range }\end{array}$ & $\begin{array}{l}\text { Data } \\
\text { source }\end{array}$ \\
\hline \multicolumn{5}{|c|}{ Roof-to-wall connection (trussed roof) } \\
\hline 3-16d twist shank toe-nails & 258.0 & 6 & $165-230$ & {$[12]$} \\
\hline 2-16d twist shank toe-nails & 230.1 & 6 & $165-230$ & [12] \\
\hline 1-16d twist shank toe-nails & 196.4 & 6 & $165-230$ & [12] \\
\hline H2.5 hurricane strap & $335.5^{*}$ & 6 & $165-230$ & [11] \\
\hline \multicolumn{5}{|l|}{ Sheathing } \\
\hline $\begin{array}{l}\text { Fastened with } 6 \mathrm{~d} \text { spiral nails } \\
150 / 300 \text { spacing }\end{array}$ & 204.8 & 4 & $130-185$ & {$[8]$} \\
\hline $\begin{array}{l}\text { Fastened with } 8 \mathrm{~d} \text { spiral nails } \\
150 / 300 \text { spacing }\end{array}$ & 252.8 & 4 & $130-185$ & [8] \\
\hline \multicolumn{5}{|l|}{ Critical truss connection (Fig. 4) } \\
\hline $\begin{array}{l}\text { Joint } 3 \\
\text { Plated connection }\end{array}$ & $275.5^{*}$ & 6 & $165-230$ & {$[14]$} \\
\hline \multicolumn{5}{|l|}{ Stick-frame member (Fig. 5) } \\
\hline $\begin{array}{l}\text { H2.5 hurricane strap with } \\
\text { stick-frame dead load }\end{array}$ & $323.3 *$ & 6 & $165-230$ & [11] \\
\hline $\begin{array}{l}5-82 \mathrm{~mm} \text { toe-nails } \\
\text { Connecting the jack rafter and } \\
\text { ceiling joist to the wall }\end{array}$ & $216.1^{*}$ & 6 & $165-230$ & {$[14]$} \\
\hline $\begin{array}{l}7-76 \mathrm{~mm} \text { nails } \\
\text { Connecting the jack rafter to } \\
\text { ceiling joist }\end{array}$ & $513.5^{*}$ & 6 & $165-230$ & [14] \\
\hline $\begin{array}{l}\text { Ridge (vertical D/C) } \\
2-82 \mathrm{~mm} \text { wire nails }\end{array}$ & $282.5^{*}$ & 6 & $165-230$ & {$[14]$} \\
\hline $\begin{array}{l}\text { Ridge (horizontal D/C) } \\
2-82 \mathrm{~mm} \text { wire nails }\end{array}$ & $314.3^{*}$ & 6 & $165-230$ & [14] \\
\hline
\end{tabular}

*Adjusted wind speed estimate determined using method described in Morrison et al. [16]; normalized using 3-d16 toe-nail resistance from Kopp et al. [12].

\subsection{Additional discussion of damage survey observations}

In addition to understanding the occurrence of different roof failure modes across residential neighborhoods, the available damage survey data was used to study important details in the failures of specific houses [14], [15]. In the damage photos, a group of houses was identified that fails in a way that disagrees with the results of the $\mathrm{D} / \mathrm{C}$ analysis for the stick-framed roof. As shown in Fig. 6, several roofs appeared to have lost their outer faces and jack rafters, while the ceiling joists remained in place. Based on the $\mathrm{D} / \mathrm{C}$ results and wind speed conversion, this failure should not occur due to the 7-nail connection joining the jack rafters to the ceiling joists. The RTWC and the connection at the ridge of the roof appear to be much more vulnerable in analysis.

Reasons for the unexpected failure of the jack rafters shown in Fig. 6 are likely related to improper or insufficient joint construction, or old building design to outdated standards. Considering system effects, a single flaw in the structure can lead to progressive, cascading 
failure of the entire roof face, although a 7-nail joint would have prohibited this. Close inspection of the damage photos suggest poor construction in many of the failed roofs. In some cases, there were nails at the jack rafter-to-ceiling joist connections, but not more than a few. In others, the jack rafters and ceiling joists were separately toe-nailed to the wall top plate, without even being in contact with one another. Fig. 7 shows the intact stick-frame structure of a roof in the same neighborhood and of the same construction style as that shown in Fig. 6(b). The circle on the figure highlights a visible space between the jack rafter and the ceiling joist.

\section{CONCLUSIONS}

Understanding the vulnerability of residential structures to extreme winds is a complex but important component of understanding tornado risk and preventing catastrophic losses. Overall, research on the predominant residential failures, ranging from sheathing loss to failure of the roof-to-wall connection, to the authors' present work related to framing failures, has agreed that the small details have the ability to make wood-framed homes resilient to extreme winds. As shown in the literature [9], [11], [12] hardware upgrades including hurricane straps for the RTWC and longer nails for sheathing will drastically improve the wind-resistance of residential roofs.

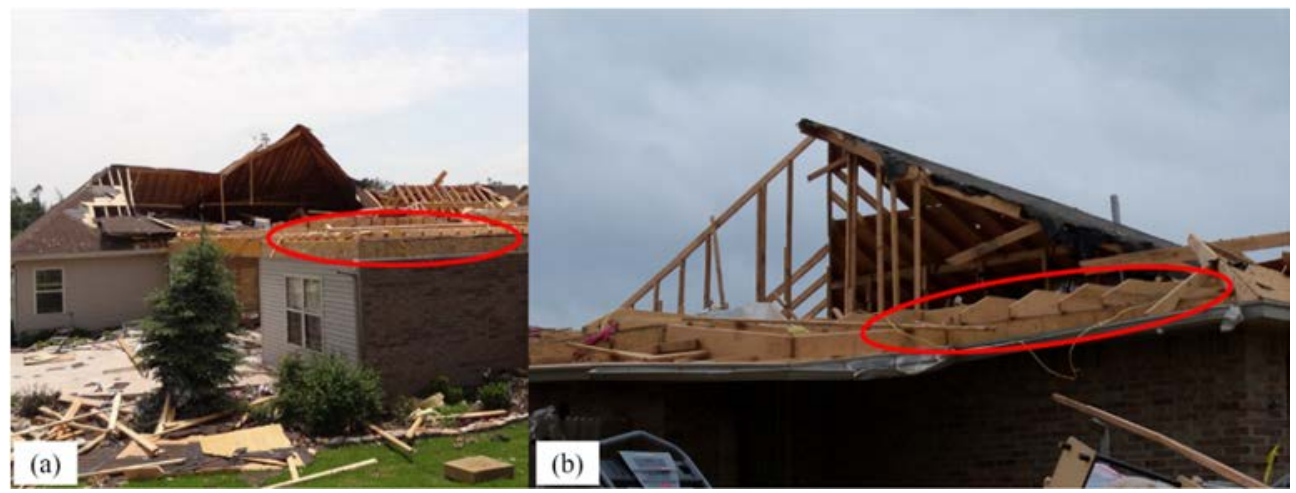

Figure 6: Framing failures in stick-frame hip roofs with intact ceiling joists. (Source: Dr. D.O. Prevatt.)

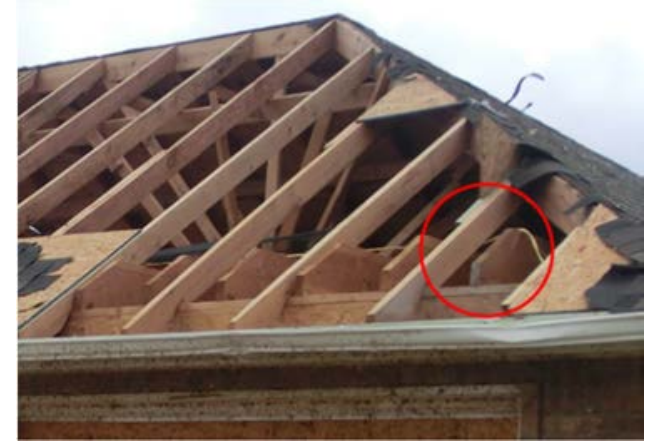

Figure 7: Intact stick-frame structure showing lack of connection between the jack rafter and ceiling joist. (Source: Dr. D.O. Prevatt.) 
The current work to understand framing failures suggests that hip roofs containing MPC trusses, with hurricane straps should be capable of withstanding higher wind speeds than currently indicated by the EF-Scale. Many of the framing failure modes observed in the damage survey data would have been objectively described as DOD6; however, the results in Table 2 show that the DOD6 wind speed are inaccurate for hip roof failures. Suggested EF-Scale adjustments in this regard are provided in Section 4.2. Analysis of the wind speeds in Table 2 also shows that trusses are highly preferable to traditional stick-frame structures. In addition to better structural configurations and internal joints, trussed structures offer the assurance of having engineered components that are manufactured in a precise manner and inspected for quality prior to delivery on site. For stick-frame structures to remain feasible, they must be subjected to a higher standard of quality control, and the prescriptive code requirements for nailed connections and member span length should be revisited to include tornado-resistant provisions.

A final point of discussion, which remains consistent throughout most damage survey literature concerns errors in construction. Understanding the structural behavior of a house under wind loads is complex even when assuming proper construction. The range of possible roof shapes, construction types, regional materials, and design standards used across the continent make understanding "typical" construction a difficult research problem. The solutions developed through research, as well as the estimated failure wind speeds and failure models only hold true for the assumed construction quality. Known errors in construction have been accounted for where possible, however damage surveys following destructive events repeatedly reveal new ways in which a house can be built incorrectly. The roof in Fig. 7 provides only one example of such errors. Code changes must be implemented - and enforced - in partnership with the construction industry to ensure that resilient houses are the top priority for all parties, and that the importance of the small details is understood.

\section{REFERENCES}

[1] Simmons, K.M., Kovacs, P. \& Kopp, G.A., Tornado damage mitigation: Benefit-cost analysis of enhanced building codes in Oklahoma. Weather, Climate, and Society, 7(2), pp. 169-178, 2015.

[2] Changnon, S.A., Tornado losses in the United States. Natural Hazards Review, 10(4), pp. 145-150, 2009.

[3] Romanic, D., Refan, M., Wu, C.-H. \& Michel, G., Oklahoma tornado risk and variability: A statistical model. International Journal of Disaster Risk Reduction, pp. 19-32, 2016.

[4] Standohar-Alfano, C.D. \& van de Lindt, J.W., Tornado risk analysis for residential wood-frame roof damage across the United States. Journal of Structural Engineering, 142(1), 2016.

[5] Environment Canada, Environment and Climate Change Canada: Enhanced Fujita Scale, Online. https://ec.gc.ca/meteo-weather. Accessed 18 Mar. 2018.

[6] Fujita, T.T., Proposed Characterization of Tornados and Hurricanes by Area and Intensity. Satellite and Mesometeorology Research Project Report 91, University of Chicago: Chicago, IL, 1971.

[7] Wind Science and Engineering Centre, A Recommendation for an Enhanced Fujita Scale, Texas Tech University: Lubbock, TX, 2006.

[8] Gavanski, E. \& Kopp, G.A., Fragility assessment of roof-to-wall connection failures for wood-frame houses in high winds. Journal of Risk and Uncertainty in Engineering Systems, 3(4), 2017. 
[9] Gavanski, E., Kopp, G.A. \& Hong, H.P., Reliability analysis of roof sheathing panels on wood-frame houses under wind loads in Canadian cities. Canadian Journal of Civil Engineering, 44, pp. 717-727, 2014.

[10] Canadian Commission on Building and Fire Codes, National Building Code of Canada, 13th ed., National Research Council of Canada: Ottawa, ON, 2010.

[11] Amini, M.O. \& van de Lindt, J.W., Quantitative insight into rational tornado design wind speeds for residential wood-frame structures using fragility approach. Journal of Structural Engineering, 140(7), 2014.

[12] Kopp, G.A., Hong, E., Gavanski, E., Stedman, D. \& Sills, D.M., Assessment of wind speeds based on damage observations from the Angus (Ontario) Tornado of 17 June 2014. Canadian Journal of Civil Engineering, 44(1), pp. 37-47, 2016.

[13] Meecham, D., Surry, D. \& Davenport, A.G., The magnitude and distribution of windinduced pressures on hip and gable roofs. Journal of Wind Engineering and Industrial Aerodynamics, 38, pp. 257-272, 1991.

[14] Stevenson, S.A., Analysis of Framing Failures in Wood-Frame Residential Roofs Under Wind Load. Master's thesis, The University of Western Ontario: London, ON, 2017.

[15] Stevenson, S.A., Kopp, G.A. \& El Ansary, A.M., Framing failures in wood-frame hip roofs under extreme wind loads. Frontiers in Built Environment, 4(6), 2018.

[16] Morrison, M.J., Kopp, G.A., Gavanski, E., Miller, C. \& Ashton, A., Assessment of damage to residential construction from the tornadoes in Vaughan, Ontario, on August 2009. Canadian Journal of Civil Engineering, 41, pp. 550-558, 2014. 